\title{
Promoter methylation of the DLC-1 gene and its inhibitory effect on human colon cancer
}

\author{
ZHENSHENG DAI $^{1}$ and YUELING JIN ${ }^{2}$ \\ ${ }^{1}$ Department of Hematology-Oncology, Shanghai Pudong Hospital Affiliated to Fudan University, Shanghai 201399; \\ ${ }^{2}$ Department of Pathology, Shanghai Health Vocational and Technical College, Shanghai 200237, P.R. China
}

Received February 17, 2013; Accepted June 7, 2013

DOI: 10.3892/or.2013.2551

\begin{abstract}
Deleted in liver cancer-1 (DLC-1), a candidate tumor suppressor gene which is inactive in liver carcinogenesis, is located at 8p21.3, where deletions are frequently found in several types of human cancer. Promoter hypermethylation is an epigenetic mechanism leading to silencing of the gene expression, which may be the primary cause for the absence of DLC-1. We investigated the expression of the DLC-1 gene and the methylation of the DLC-1 gene in colon cancer cell lines (Caco-2, LoVo and HT-29). The data showed that reduced or undetectable levels of DLC-1 mRNA were found in HT-29 by reverse transcription-polymerase chain reaction (RT-PCR). By contrast, the DLC-1 gene was significantly expressed in Caco- 2 and LoVo cells. These findings were in agreement with the data obtained from western blot analysis. To further determine whether aberrant methylation is a contributing factor to transcriptional inactivation of DLC-1 in HT-29, the methylation of promoter was examined using methylation-specific PCR and sodium bisulfite genomic sequencing in LoVo and HT-29 cells, which suggests that promoter hypermethylation accounts for silencing of the DLC-1 gene in HT-29 cells. Since DLC-1 is a candidate tumor suppressor gene, we sought to determine whether DLC-1 expression is associated with cell proliferation in colon cancer cell lines. RNA interference techniques were adopted to inhibit DLC-1 expression in the LoVo cell line and resulted in inhibition of cell growth and reduced colony formation. Collectively, our observations suggest that hypermethylation is responsible for abrogating the function of the DLC-1 gene in colon cancer and indicate a role of DLC-1 in colon carcinogenesis.
\end{abstract}

\section{Introduction}

Deleted in liver cancer-1 (DLC-1) is a tumor suppressor gene, identified through representational difference analysis, and has

Correspondence to: Dr Zhensheng Dai, Department of Hematology-Oncology, Shanghai Pudong Hospital Affiliated to Fudan University, 2008 Gongwei Road, Huinan Town, Pudong New District, Shanghai 201399, P.R. China

E-mail: zhenshengdai@yahoo.com.cn

Key words: deleted in liver cancer-1, methylation, colon cancer, tumorigenicity, RNA interference been found to be localized at the short arm of chromosome 8 , at p21.3, where deletions are frequently found in several types of human cancer, such as nasopharyngeal carcinoma (1), breast cancer (2), colorectal cancer (3), lung cancer (4), hepatocellular carcinoma (HCC) (5) and medulloblastoma (6). Promoter hypermethylation, an epigenetic mechanism leading to the silencing of the gene expression $(7,8)$, may be the reason for the absence of DLC-1. Previous studies indicated that promoter hypermethylation of DLC-1 is found in HCC, colon, breast and prostate cancer (9). Methylation of DLC-1 is also common in hematologic malignancies; it has been found in $87 \%$ of non-Hodgkin's lymphomas (NHLs) and multiple myeloma tumors or tumor cell lines, but not in benign hyperplasia. It has also been proposed that DLC-1 methylation status in NHLs could be used as a diagnostic marker (10). Normally, there are three mechanisms leading to gene silencing: mutation, genomic deletion and promoter methylation. Mutation, as a cause of DLC-1 inactivation, is effectively ruled out due to the low rate of happening (11). This suggests that either genomic deletion or promoter methylation is the primary cause for altered expression or inactivation of the DLC-1 gene (12). Though hypermethylation is responsible for the silencing of the DLC-1 gene in a limited portion of breast cancer cases, transfection of the gene into DLC-1 deficient T-47D cells raised the DLC-1 mRNA level and resulted in inhibition of cell growth and reduced colony formation capacity, which indicate a role of DLC-1 in breast cancer carcinogenesis (13). Nevertheless, cells derived from other types of cancer such as lung, liver or ovarian cancer are also highly sensitive to reactivation of DLC-1 function $(11,14)$. Recent studies have shown that restoration of the DLC-1 in breast cancer cells resulted in the inhibition of migration and invasion. In addition, Chan et al (15) reported that DLC-1 expression reduced the migration and invasiveness of SMMC-7721 HCC cells. There is a strong potential for an effective therapy based on DLC-1 transfer to tumor cells. However, DLC-1 has been little examined in colon cancer; thus, studies on DLC-1 expression and the mechanism of DLC-1 gene inactivation may be necessary to elucidate the possible role of DLC-1 in colorectal tumor development. In the present study, we explored the involvement of DLC-1 promoter hypermethylation in colorectal tumors. Additionally, we investigated the effects of DLC-1 on colon cancer cell proliferation by RNA interference (RNAi) techniques. 
Table I. The primers used and conditions of PCR amplification.

\begin{tabular}{|c|c|c|c|}
\hline Primer & $5^{\prime}-3^{\prime}$ sequence & PCR conditions & $\begin{array}{l}\text { Size of amplified } \\
\text { products (bp) }\end{array}$ \\
\hline DLC-1 (RT-PCR) & $\begin{array}{l}\text { GGACACCATGATCCTAACAC } \\
\text { CTCATCCTCGTCTGAATCGT }\end{array}$ & $\begin{array}{l}94 / 3 \mathrm{~min}(94 / 30 \mathrm{sec}, 52 / 30 \mathrm{sec} \\
72 / 40 \mathrm{sec}) \times 42,72 / 7 \mathrm{~min}\end{array}$ & 252 \\
\hline$\beta$-actin (RT-PCR) & $\begin{array}{l}\text { CGTGGCCTTAGCTGTGCT } \\
\text { TGTGCATAAAGTGTAAGTGTATAAGCA }\end{array}$ & $\begin{array}{l}94 / 3 \min (94 / 30 \mathrm{sec}, 50 / 30 \mathrm{sec}, \\
72 / 40 \mathrm{sec}) \times 42,72 / 7 \mathrm{~min}\end{array}$ & 457 \\
\hline $\begin{array}{l}\text { DLC-1 (unmethylation } \\
\text { specific primers) }\end{array}$ & $\begin{array}{l}\text { TTTTTTAAAGATTGAAATGAGGGAGTG } \\
\text { AAACCCAACAAAAAAACCCAACTAACA }\end{array}$ & $\begin{array}{l}94 / 3 \mathrm{~min}(94 / 30 \mathrm{sec}, 52 / 30 \mathrm{sec}, \\
72 / 40 \mathrm{sec}) \times 45,72 / 7 \mathrm{~min}\end{array}$ & 172 \\
\hline $\begin{array}{l}\text { DLC-1 (methylation } \\
\text { specific primers) }\end{array}$ & $\begin{array}{l}\text { TTTAAAGATCGAAACGAGGGAGCG } \\
\text { CCCAACGAAAAACCCGACTAACG }\end{array}$ & $\begin{array}{l}94 / 3 \mathrm{~min}(94 / 30 \mathrm{sec}, 52 / 30 \mathrm{sec}, \\
72 / 40 \mathrm{sec}) \times 45,72 / 7 \mathrm{~min}\end{array}$ & 178 \\
\hline $\begin{array}{l}\text { Bisulfite treated } \\
\text { DNA (PCR primer) }\end{array}$ & $\begin{array}{l}\text { GTTTTTAGTTAGGATATGGT } \\
\text { CTTCTTTCTACACATCAAACA }\end{array}$ & $\begin{array}{l}94 / 3 \mathrm{~min}(94 / 30 \mathrm{sec}, 52 / 30 \mathrm{sec}, \\
72 / 40 \mathrm{sec}) \times 45,72 / 7 \mathrm{~min}\end{array}$ & 292 \\
\hline$\beta$-actin & $\begin{array}{l}\text { CCCTGGACTTCGAGCAAGAGAT } \\
\text { GTTTTCTGCGCAAGTTAGG }\end{array}$ & $\begin{array}{l}95 / 2 \min (95 / 1 \min , 60 / 1 \mathrm{~min} \\
72 / 1 \min ) \times 35\end{array}$ & 531 \\
\hline
\end{tabular}

RT-PCR, reverse transcription-polymerase chain reaction.

\section{Materials and methods}

Colon cancer cell lines. Human colon cancer cell lines, Caco-2, HT-29 and LoVo, were obtained from the Shanghai Institute of Cell Biology, Chinese Academy of Sciences. Cells were cultured in RPMI-1640 (Sigma, St. Louis, MO, USA) and antibiotics, supplemented with $10 \%$ fetal bovine serum and $100 \mathrm{U} / \mathrm{ml}$ of penicillin and streptomycin at $37^{\circ} \mathrm{C}$ in a humidified $5 \% \mathrm{CO}_{2}$ atmosphere and stored at $-20^{\circ} \mathrm{C}$.

DNA/RNA extraction. By standard methods, genomic DNA was isolated by digestion with Proteinase $\mathrm{K}$ followed by phenol:chloroform (1:1) extraction and ethanol precipitation from Caco-2, HT-29 and LoVo cell lines. Total-RNA extraction was performed using TRIzol reagent (Invitrogen Life Technologies, Groningen, The Netherlands) according to the manufacturer's instructions. To avoid the genomic DNA contamination, RNA samples were treated with DNase I (RNase-free) (Takara Bio, Inc., Shiga, Japan) for $20 \mathrm{~min}$ at $37^{\circ} \mathrm{C}$. The enzyme was heat inactivated and the RNA was ethanol precipitated following phenol chloroform extraction. Following precipitation, the RNA was resuspended in $10 \mu \mathrm{l}$ of diethylpyrocarbonate (DEPC)-treated water and stored at $-80^{\circ} \mathrm{C}$.

Reverse transcription $(R T)$ reaction. RNA (5 $\mu \mathrm{g})$ was used as template in the first strand complementary DNA (cDNA) synthesis in a $20 \mu \mathrm{l}$ reaction volume, which consisted of oligo-dT primer (0.2 $\mu \mathrm{g} /$ reaction), dNTP $(0.5 \mathrm{mM}$ of each), avian myeloblastosis virus reverse transcriptase (AMV RT; Promega Corporation, Madison, WI, USA) (20 U/reaction), RNasin (Takara Bio) (20 U/reaction). The reaction was incubated at $42^{\circ} \mathrm{C}$ for $60 \mathrm{~min}$, followed by heating at $99^{\circ} \mathrm{C}$ for 5 min. Reactions in which pure water replaced the RNA were used as RT-negative controls.
Polymerase chain reaction (PCR) amplification and electrophoresis. All primers and amplification conditions used in this study are listed in Table I. Single round $\beta$-actin amplification was used to demonstrate RNA integrity and the RT performance. The reaction mixture consisted of the template (50-100 $\mu \mathrm{g}$ of cDNA), dNTP (0.2 mM of each), Taq DNA polymerase (Promega Corporation) (0.625 U/reaction) and a selected primer pair ( $20 \mathrm{pmol} / \mathrm{primer} /$ reaction) in a total volume of $25 \mu \mathrm{l}$. The final products were analyzed by electrophoresis on $2 \%$ agarose gels containing ethidium bromide.

Sodium bisulfite treatment. Genomic DNA $(2 \mu \mathrm{g})$ was denatured with $0.3 \mathrm{M} \mathrm{NaOH}$ for $10 \mathrm{~min}$ at $37^{\circ} \mathrm{C}$ and mixed with $30 \mu \mathrm{l}$ of $10 \mathrm{mM}$ hydroquinone (Sigma), $510 \mu \mathrm{l}$ of $3.0 \mathrm{M}$ $\mathrm{NaHSO}_{3}$ (pH 5.0; Sigma), covered with paraffin oil, then deaminated in the dark for $16 \mathrm{~h}$ at $50^{\circ} \mathrm{C}$. To use, $10 \mathrm{mM}$ hydroquinone and 3.0 $\mathrm{M} \mathrm{NaHSO}_{3}(\mathrm{pH}$ 5.0) were freshly prepared and mixed. Bisulfite-treated DNA was purified using a Wizard DNA Clean-Up System (Promega Corporation). Subsequently, purified DNA samples were desulfonated with $0.3 \mathrm{M} \mathrm{NaOH}$ for $5 \mathrm{~min}$ at room temperature, neutralized with ammonium acetate, ethanol precipitated and resuspended in $20 \mu \mathrm{l}$ Tris-EDTA buffer.

Methylation-specific PCR (MSP) and sequencing. To determine whether the loss of DLC-1 expression was associated with promoter hypermethylation, we used MSP to detect the methylation status of the $5^{\prime} \mathrm{CpG}$ island. Bisulfite-treated DNA was amplified by PCR with methylation status-specific primer pairs. The primer sequences for the MSP and amplification conditions used in this study are listed in Table I. The sodium bisulfite reaction converts unmethylated cytosine in DNA to uracil while leaving the methylcytosine unchanged, so that methylated and unmethylated alleles can be distinguished by MSP. Bisulfite-treated DNA $(8 \mu \mathrm{l})$ was subjected to PCR using 
Table II. Oligonucleotide sequences of siRNA.

\begin{tabular}{lcc}
\hline Group & Sequence of siRNA nucleotides & Sites \\
\hline pGCsil- & 5'-GGAACTGAAGAGACGCAAT-3' & 1596-1614 \\
DLC-1 & & \\
Control & 5'-TTCTCCGAACGTGTCACGT-3' & - \\
\hline
\end{tabular}

bisulfite treated DNA PCR primer (the primer can amplify both the sequences methylated and unmethylated) (Table I), a 292 bp fragment, particularly for the upstream region of the basic promoter of DLC-1 was amplified and PCR product was sequenced.

Short hairpin RNA (shRNA) preparation and plasmid construction. In order to construct two plasmids, two pairs of shRNA sequence were designed, one is according to the DLC-1 sequence in the GenBank (AF035119), as pGCsiDLC-1, another sequence of shRNA has no homology with human sequence, as a control group. Each pair contained a unique 19-nt double-stranded sequence that is separated by a loop of 9-nt sequence (ttcaagaga). Following purification and restriction digestion, the oligonucleotides were ligated into plasmid pGCsi with polymerase III U6 promoter, purchased from GeneChem Inc, China. After amplifying the plasmids into E.coli, the selected clones with the shRNA insert were selected and purified with plasmid purification kit (Promega Corporation). The oligonucleotide sequences of siRNA are listed in Table II.

Transfection assay. To generate DLC-1 transfected DLC-1 cells, $3 \mu \mathrm{g}$ of plasmid DNA were transfected in $1 \times 10^{5}$ cells in a 60-mm dish using Lipofectamine ${ }^{\circledR} 2000$ (Invitrogen Life Technologies, Carlsbad, CA, USA) according to the manufacturer's instructions. Selection for transfected cells was carried out in a medium containing $400 \mu \mathrm{g} / \mathrm{ml} \mathrm{G} 418$ (Geneticin; Life Technologies, Inc., USA).

Western blot analysis. Experiments were conducted in three groups, the pGCsiDLC-1, the mock and the control group. Following transfection for 24 and $48 \mathrm{~h}$, LoVo cells $\left(10 \times 10^{6}\right)$ were harvested and lysed in $60 \mu \mathrm{l}$ cell lysis reagent, containing $50 \mathrm{mmol} / \mathrm{l}$ Tris- $\mathrm{HCl}$ (pH 8.0), $150 \mathrm{mmol} / \mathrm{l} \mathrm{NaCl}, 100 \mu \mathrm{g} / \mathrm{ml}$ phenylmethylsulfonyl fluoride (PMSF) and 1\% TritonX-100. Equal amounts of total protein were separated by $5 \%$ sodium dodecyl sulphate-polyacrylamide gel electrophoresis (SDS-PAGE) and then transferred onto polyvinylidene fluoride (PVDF). After blocking in a 5\% non-fat dry milk solution in washing buffer containing $10 \mathrm{mmol} / \mathrm{l}$ Tris ( $\mathrm{pH} \mathrm{7.6)}$, $150 \mathrm{mmol} / 1 \mathrm{NaCl}$ and $0.05 \%$ Tween-20, membranes were incubated for $1 \mathrm{~h}$ at room temperature with human monoclonal anti-DLC-1 (1:200; clone 3; BD Biosciences Pharmingen, San Diego, CA, USA) as primary antibodies, washed 3 times, incubated again with bovine anti-mouse $\operatorname{IgG}$ (1:2,500; Santa Cruz Biotechnology, Inc., Santa Cruz, CA, USA) as second antibody. $\beta$-tublin (1:300) staining served as the internal standard for all membranes.

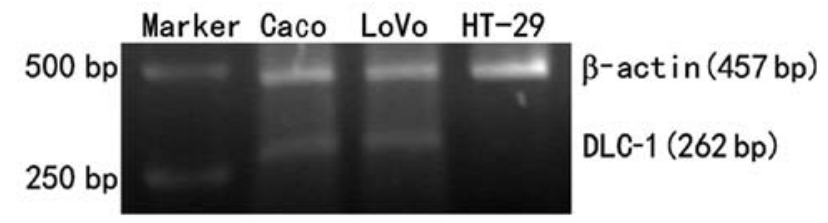

Figure 1. Level of DLC-1 mRNA in colon cancer cell lines. DLC-1 mRNA levels of three human colon cancer cell lines were assessed by reverse transcription-polymerase chain reaction. LoVo and Caco-2 cells were found to have DLC-1 expression. HT-29 has no expression. $\beta$-actin was used as an internal control.

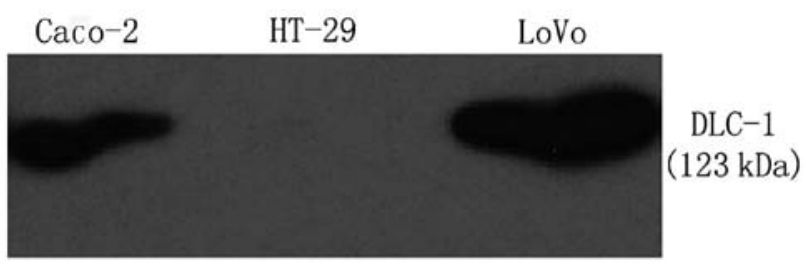

Figure 2. DLC-1 protein expression in colon cancer cell lines. In order to detect the protein expression of DLC-1 in these cells, western blot analysis was performed and showed that the gene was expressed in LoVo and Caco-2 cells at the protein level. No expression of DLC-1 was detected in HT-29. The sizes of the western blot analysis products were $123 \mathrm{kDa}$ for DLC- 1 . The results were in agreement with the results obtained from reverse transcription-polymerase chain reaction.

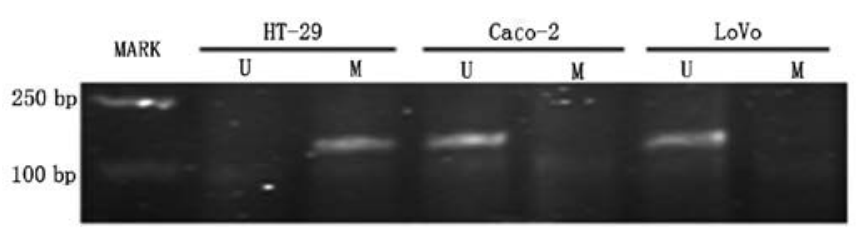

Figure 3. Methylation-sensitive polymerase chain reaction (PCR) analysis of the DLC-1 CpG island in colon cancer cell lines. We used methylation-specific PCR (MSP) to detect the methylation status of the 5' $\mathrm{CpG}$ island. Bisulfitetreated DNA was amplified by PCR with methylation status-specific primer pairs. Primer sets used for amplification are designated as unmethylated (U) and methylated (M). Among these cell lines, PCR with methylated primers show that HT-29 cells have methylated forms of DLC-1, but Caco-2 and LoVo cells showed the unmethylation-specific band. M, MSP; U, unmethylationspecific PCR.

MTT assay. The transfected cells were plated in 96-well microtiter plates at a density of $1 \times 10^{4}$ cells/well. Cells were further cultured for 24, 36 and 48 h respectively, after which the medium was replaced with $100 \mu \mathrm{l}$ of fresh serum-free medium containing $50 \mu \mathrm{g}$ MTT. Four hours later, the color reaction was quantified with an ELISA plate reader at a test wavelength of $570 \mathrm{~nm}$ and a reference wavelength of $630 \mathrm{~nm}$. The experiment was repeated three times independently.

Colony formation assay. The cells stably transfected with DLC-1 and control cells were seeded into six-well plates at a density of $1 \times 10^{4}$ cells/well, the culture medium contained $500 \mu \mathrm{g} / \mathrm{ml} \mathrm{G} 418$ (Geneticin; Life Technologies, Inc). After culturing for two weeks, the G418-resistant colonies were washed twice with phosphate-buffered saline (PBS), stained with Giemsa, and the colony formation efficiency was tested. For soft agar colony assays, the pGCsil-DLC-1, the mock and the control group were mixed with RPMI-1640 complete 

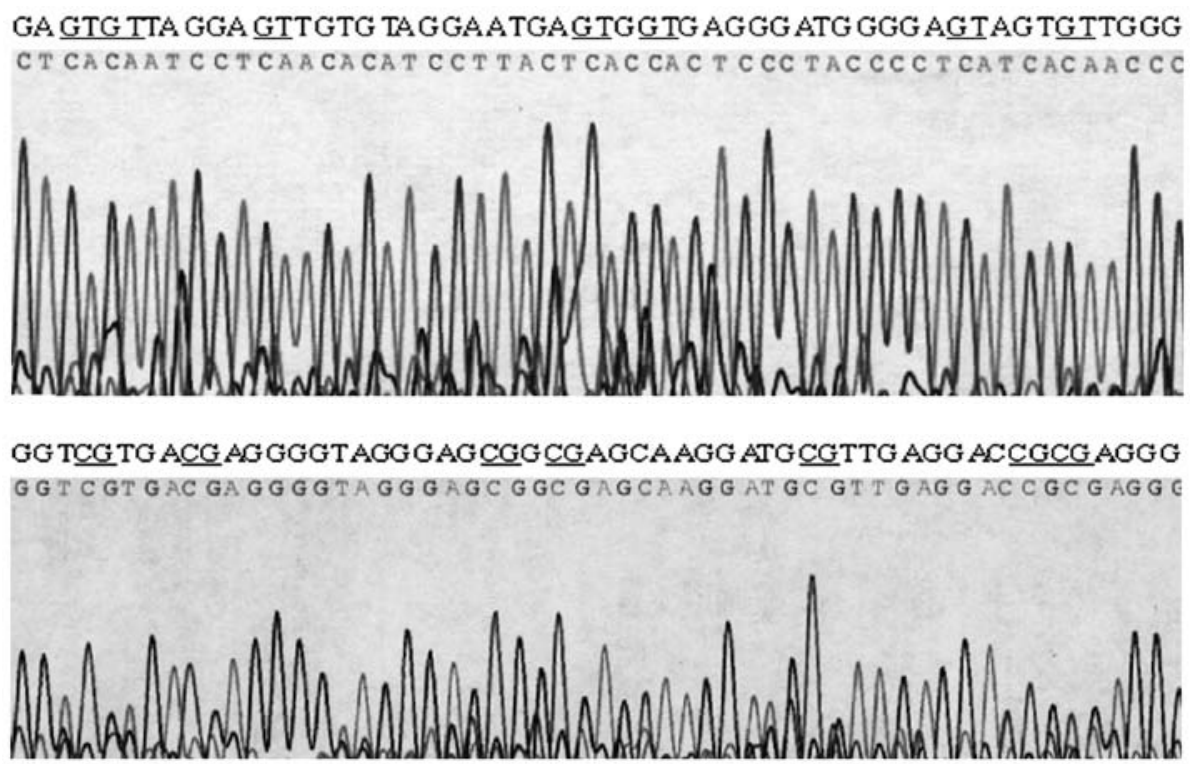

Figure 4. Bisulfite sequencing of LoVo and HT-29 cells. A 292 bp fragment of the DLC-1 promoter region was sequenced in LoVo and HT-29 cells. Examples of an unmethylated DLC-1 5'CpG island in sample LoVo (upper) and highly methylated CpG island in sample HT-29 (down) as determined by bisulfite sequencing analysis. Lines, positions of $\mathrm{CpG}$ dinucleotides.

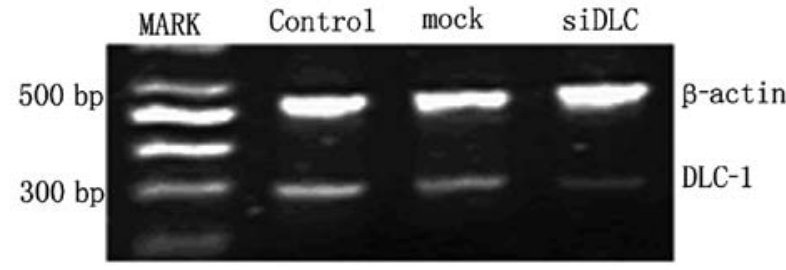

Figure 5. The mRNA expression of DLC-1 in LoVo cells at $48 \mathrm{~h}$ post-transfection was examined by semiquantitative reverse transcription-polymerase chain reaction. Relative DLC-1 mRNA levels normalized by internal control $\beta$-actin. Compared with the control group, DLC-1 mRNA expression was reduced.

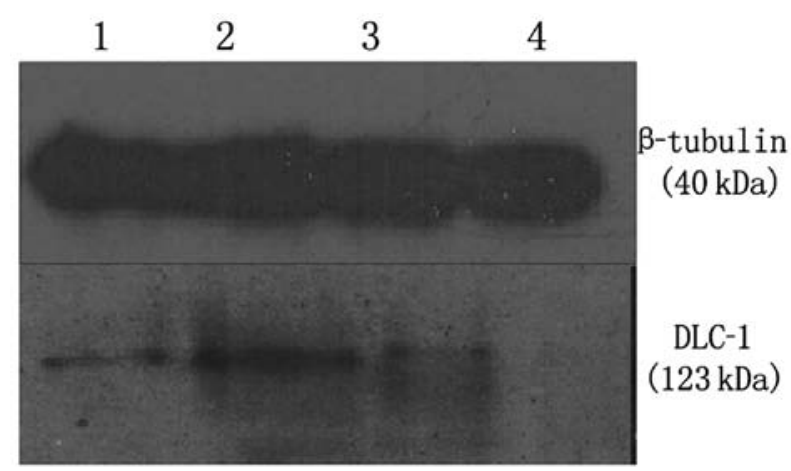

Figure 6. RNA interference induced downregulation of cellular DLC-1 protein. The knockdown efficiencies of DLC-1 in LoVo cells were analyzed by western blot analysis. Relative protein level was normalized by internal control $\beta$-tubulin. DLC-1 protein expression was downregulated after tansfection, particularly after $48 \mathrm{~h}$. Lane 1, mock (no short hairpin RNA); lane 2, control; lane 3, pGCsi DLC-1/24 h; lane 4, pGCsi DLC-1/48 h. The figure shows a representative result from at least three independent experimental data with similar results.

medium containing $0.4 \%$ agar and placed over $0.6 \%$ of basal agar in six-well plates. Cells were grown for two weeks and colonies were visualized microscopically and photographed.

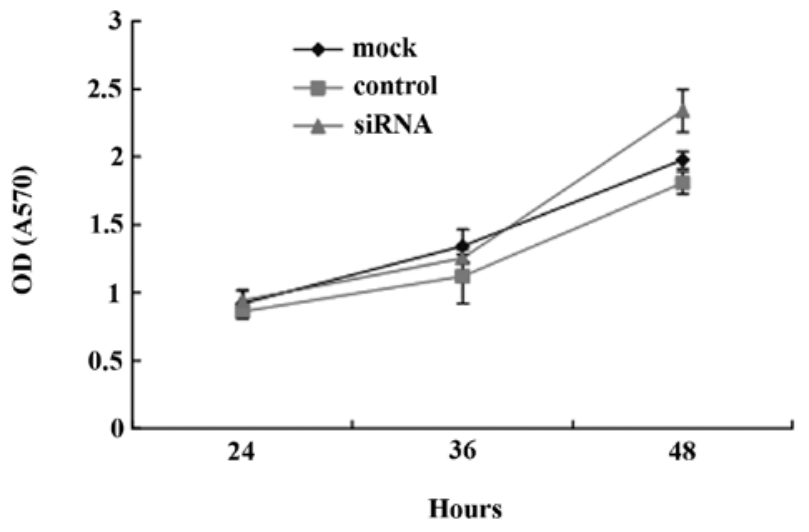

Figure 7. Cell proliferation assessed by MTT assay in different transfected cell lines. To examine the effect of DLC-1 on LoVo cell growth, pGCsiDLC-1, control group and mock cell lines were cultured for 24,36 and $48 \mathrm{~h}$ respectively. At $48 \mathrm{~h}$, the proliferation rate of LoVo cells increased significantly compared to the mock and control group $(\mathrm{P}<0.01)$. No significant difference was observed between the mock and the control group.

\section{Results}

Detection of DLC-1 expression in colon cancer cell lines. RT-PCR was performed in Caco-2, LoVo and HT-29 cells to examine the expression of DLC-1 in colon cancer cell lines. To validate the PCR results, the same cDNA was amplified for $\beta$-actin. All the cell lines were positive for $\beta$-actin, which indicates both RNA preparation and cDNA synthesis were successful. Caco-2 and LoVo colon cancer cell lines were all positive for DLC-1 mRNA and a band of $262 \mathrm{bp}$, but low levels or absence of DLC-1 mRNA were observed in HT-29 cells (Fig. 1). In order to detect the protein expression of DLC-1 in these cells, western blot analysis was performed and the results were in agreement with the results obtained from RT-PCR. Loss of DLC-1 protein expression was detected in HT-29, Caco-2 and LoVo revealed a fragment of $123 \mathrm{kDa}$ (Fig. 2). 


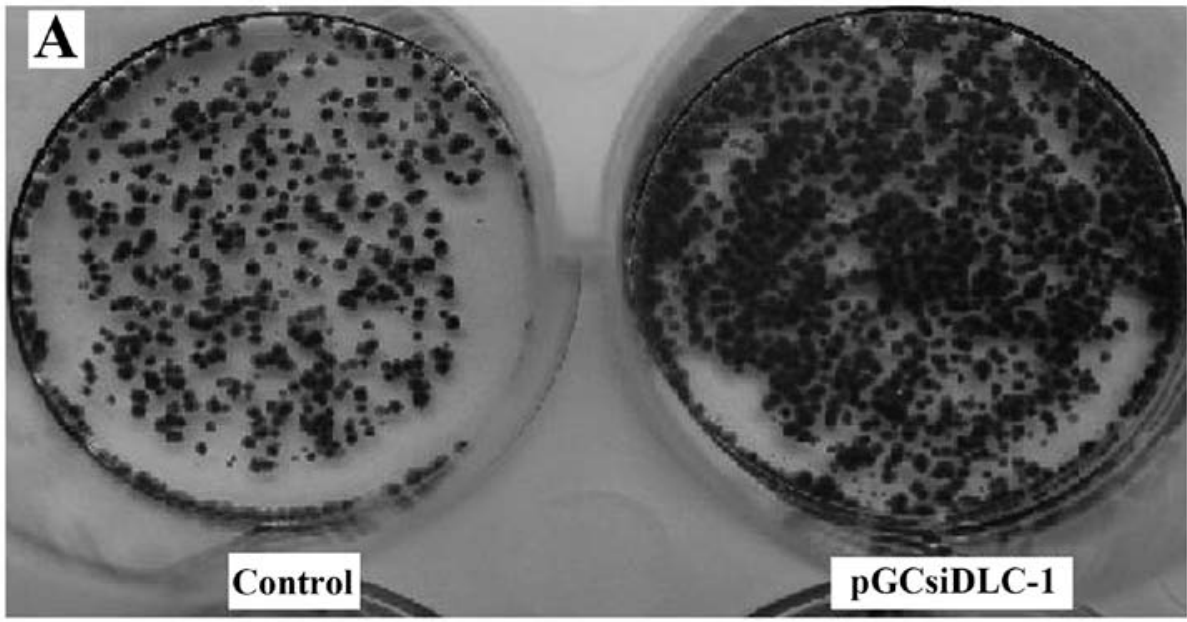

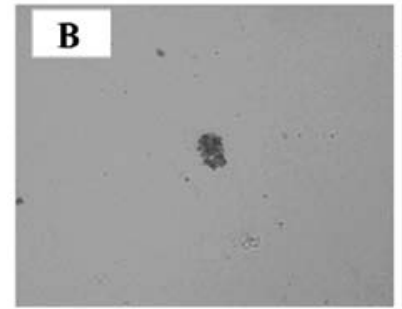

Mock

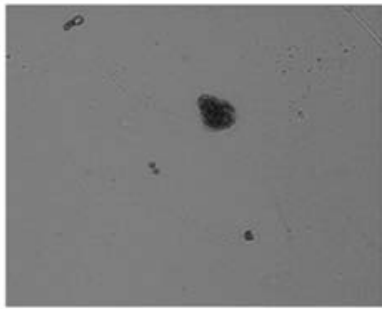

Control

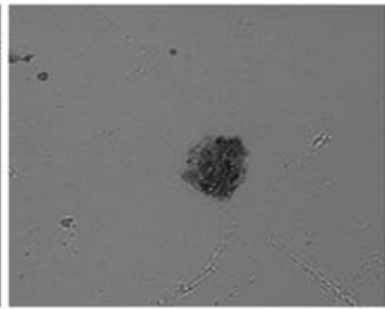

pGCsiDLC-1

Figure 8. Colony-formation assays. (A) To test the effect of DLC-1 on colony formation, cells transfected with DLC-1 and control vector were cultured in G418 for two weeks. The images are of flasks containing control LoVo cell lines and cells transfected with pGCsiDLC-1. A significant reduction in both colony number and size of G418-resistant colonies was observed in the control LoVo cell lines compared to cells transfected with pGCsiDLC-1. (B) Inhibition of expression of DLC-1 induces LoVo cell anchorage-independent growth. Cells were grown in soft agar (0.4\%), the colonies were visualized microscopically after two weeks and photographed from one representative experiment.

Methylation of the DLC-1 gene promoter in colon cancer cell lines. To determine whether the loss of DLC-1 expression was mediated by promoter hypermethylation in human colon cancer cell lines, MSP was performed on Caco-2, LoVo and HT-29 cells. Representative results are shown in Fig. 2. All cells exhibited the bands that correspond to either unmethylated (178 bp) or methylated (172 bp) CpG island. PCR with methylated primers showed that HT-29 has methylated forms of DLC-1, which showed no expression or low levels of DLC-1 expression. On the other hand, the unmethylated band was observed in Caco-2 and LoVo cells (Fig. 3). To further confirm the methylation status as well as to determine whether the loss of DLC-1 expression was mediated by promoter hypermethylation in colon cancer cell lines, a $292 \mathrm{bp}$ fragment of the DLC-1 promoter region was sequenced on LoVo and HT-29 cells. In agreement with the results obtained from MSP study, $6 \mathrm{CpG}$ dinucleotides in LoVo cell were unmethylated, whereas HT-29 cells showed extensive hypermethylation at these $\mathrm{CpG}$ dinucleotides (Fig. 4).

Inhibition of DLC-1 gene expression by shRNA expression vectors. The knockdown efficiencies of DLC-1 specific shRNAs in LoVo cells were analyzed by semiquantitative RT-PCR. Relative DLC-1 mRNA levels were normalized by internal control $\beta$-actin after transfection. Compared with the mock and the control group, the DLC-1 mRNA expression was reduced in the pGCsiDLC-1 LoVo cells, but it was not different in the mock and the control group (Fig. 5). The expression of DLC-1 protein can reflect post-transcription level of the DLC-1 gene. The knockdown efficiencies of DLC-1 protein in LoVo cells were analyzed by western blot analysis. $\beta$-tubulin protein expression was used to normalize the expression of DLC-1. The results showed DLC-1 protein expression to be downregulated following transfection, particularly after 48 h (Fig. 6).

Effects of DLC-1 expression on cell growth in LoVo cells. To determine whether decreased DLC-1 expression may change the rate of LoVo cell proliferation, DLC-1 RNAi recombinant vector was transfected into LoVo cells to downregulate DLC-1 expression and MTT assay was carried out to test cell proliferation. Fig. 7 shows that after the cells were transfected with pGCsiDLC-1, the proliferation rate of the LoVo cells increased significantly at $48 \mathrm{~h}$ compared to the control and the mock group $(\mathrm{P}<0.01)$. No significant difference of growth inhibition was observed between the mock and the control group. To further assess the time of DLC-1 inhibitory effects, we tested the effect of DLC-1 on colony formation of LoVo cells; cells transfected with pGCsiDLC-1 and control vector were cultured in G418 for two weeks and the colony number was counted on Giemsa-stained dishes. A significant increase both in colony number and size of G418-resistant colonies was observed in transfection LoVo cell lines compared to the control group (Fig. 8A) and for soft agar assays, cells transfected with pGCsiDLC-1 formed colonies more quickly than the mock and the control group (Fig. 8B). 


\section{Discussion}

A candidate tumor suppressor gene referred to as DLC-1 was isolated from human HCC by PCR-based subtractive hybridization approach (16). Determination of the DLC-1 cDNA sequence shows that it is the human homologue of rat p122, which has been found to act as a Rho GTPase protein (RhoGAP) (17). DLC-1 contains a RhoGAP domain, and two other functional motifs, a sterile alpha motif (SAM) domain and a StaR-related lipid transfer (START) domain. Overexpression of p122 in cultured cells induces morphological changes in adherent cells and the detachment of cells from the substratum (18). It was originally reported that the human DLC-1 gene is a regulator of the Rho family of small GTPases, indicating that the DLC-1 gene controls actin cytoskeleton organization, membrane trafficking, gene expression, cell proliferation, malignant transformation and metastasis (19). The length of the human DLC-1 gene is $50 \mathrm{~kb}$ and consists of 14 exons, the sequence at the 5 'end of the first exon is GC-rich and typical of a $\mathrm{CpG}$ island, it has a $63 \% \mathrm{G}+\mathrm{C}$ content, that encompasses the transcription start site and harbors several potential transcription factor-binding sites (20). Results have shown that the $5^{\prime} \mathrm{CpG}$ island of the DLC- 1 gene is unmethylated in DNA from normal cells but is methylated in DNA from several tumor cell lines that have been shown to lack detectable levels of DLC-1 mRNA. Almost all CpG sites within DLC-1 $\mathrm{CpG}$ island were methylated in gastric cancer cells $(21,22)$. This methylation promotes the binding of proteins that recognize methyl-CpGs and lead to alterations in chromatin structure that repress transcription.

In this study, we first investigated the expression of the DLC-1 in colon cancer cell lines. Levels of DLC-1 expression were reduced or undetectable in HT-29, while high levels of DLC-1 were detected in Caco-2; RT-PCR and western blot analysis demonstrated the expression of the DLC-1 gene in LoVo was positive both at the mRNA and the protein level. The findings agree with those reported by Ullmannova and Popescu (23). Since mounting evidence demonstrated that promoter hypermethylation of certain tumor-suppressor genes can inhibit gene transcription, the methylation status of the promoter region of the DLC-1 gene was examined by using MSP and sodium genomic sequencing in the three colon cancer cell lines. These findings confirmed that the promoter of DLC-1 is hypermethylated in the HT-29 colon cancer cell line, which does not have detectable levels of DLC-1 mRNA and protein expression. On the contrary, no methylation was found in LoVo and Caco-2 cells which are positive for DLC-1 expression. It is agreed that with the loss of mRNA expression, epigenetic silencing by mechanisms such as aberrant methylation of the DLC-1 promoter might be responsible, particularly in colon cancer. Mutations of DLC-1 in other types of cancer are low $(24,25)$. DLC-1 inactivation caused by methylation was not rare in colon cancer cell lines; thus, promoter hypermethylation might be a major mechanism responsible for the silencing of DLC-1 in a variety of solid tumors and hematological malignancies.

The investigation by Yuan et al (26) demonstrated that transfer of DLC-1 into three DLC-1 negative human non-small cell lung carcinoma cell lines caused a significant inhibition in cell proliferation and a decrease in colony formation. DLC-1 restoration in DLC-1 negative SNU-368 human HCC cells resulted in inhibition of cell proliferation and migration, and induction of cell morphological changes. In addition, significant reduction of tumorigenicity was shown in nude mice, which indicates DLC-1 plays the role of a tumor suppressor gene. To understand whether DLC-1 expression affects colon cancer cell growth, eukaryotic expression plasmid vectors of shRNA specific for the DLC-1 gene were designed and generated. The plasmid vectors were transfected into LoVo cells by cation liposomes to inhibit DLC-1 expression in the LoVo cell line which highly expresses the DLC-1 gene. Data also showed that lack of DLC-1 expression resulted in the inhibition of cell growth and reduced colony formation. Forty-eight hours after the cells were transfected, the proliferation rate of the LoVo cells increased significantly compared to that of the control and the mock transfection group $(\mathrm{P}<0.01)$; a significant increase in both colony number and size of colonies was also observed in transfected cells. Collectively, our observations suggest that hypermethylation is responsible for abrogating the function of the DLC-1 gene in colon cancer and indicate an inhibitory effect on colon cancer cell growth in vitro.

\section{Acknowledgements}

This study was supported by grants from the Shanghai Bureau of Health, P.R. China (no. 2010052).

\section{References}

1. Zhang X, Li W, Li H, et al: Genomic methylation profiling combined with gene expression microarray reveals the aberrant methylation mechanism involved in nasopharyngeal carcinoma taxol resistance. Anticancer Drugs 23: 856-864, 2012.

2. Muehlich S, Hampl V, Khalid S, et al: The transcriptional coactivators megakaryoblastic leukemia $1 / 2$ mediate the effects of loss of the tumor suppressor deleted in liver cancer 1. Oncogene 31: 3913-3923, 2012.

3. Low JS, Tao Q, Ng KM, et al: A novel isoform of the $8 \mathrm{p} 22$ tumor suppressor gene DLC1 suppresses tumor growth and is frequently silenced in multiple common tumors. Oncogene 30: 1923-1935, 2011.

4. Castro M, Grau L, Puerta P, et al: Multiplexed methylation profiles of tumor suppressor genes and clinical outcome in lung cancer. J Transl Med 8: 86, 2010.

5. Zimonjic DB and Popescu NC: Role of DLC1 tumor suppressor gene and MYC oncogene in pathogenesis of human hepatocellular carcinoma: Potential prospects for combined targeted therapeutics (Review). Int J Oncol 41: 393-406, 2012.

6. Pang JC, Chang Q, Chung YF, et al: Epigenetic inactivation of DLC-1 in supratentorial primitive neuroectodermal tumor. Hum Pathol 36: 36-43, 2005.

7. Flanagan S, Lee M, Li CC, et al: Promoter methylation analysis of IDH genes in human gliomas. Front Oncol 2: 193, 2012.

8. Uhm KO, Lee ES, Lee YM, et al: Aberrant promoter CpG islands methylation of tumor suppressor genes in cholangiocarcinoma. Oncol Res 17: 151-157, 2008.

9. Park SW, Durkin ME, Thorgeirsson SS and Popescu NC: DNA variants of DLC-1, a candidate tumor suppressor gene in human hepatocellular carcinoma. Int J Oncol 23: 133-137, 2003.

10. Shi H, Guo J, Duff DJ, et al: Discovery of novel epigenetic markers in non-Hodgkin's lymphoma. Carcinogenesis 28: 60-70, 2007.

11. Liao YC, Shih YP and Lo SH: Mutations in the focal adhesion targeting region of deleted in liver cancer-1 attenuate their expression and function. Cancer Res 68: 7718-7722, 2008.

12. Sabbir MG, Wigle N, Loewen S, et al: Identification and characterization of Dlc1 isoforms in the mouse and study of the biological function of a single gene trapped isoform. BMC Biol 8: 17, 2010. 
13. Teramoto A, Tsukuda K, Yano M, et al: Less frequent promoter hypermethylation of $D L C-1$ gene in primary breast cancers. Oncol Rep 12: 141-144, 2004

14. Syed V, Mukherjee K, Lyons-Weiler J, et al: Identification of ATF-3, caveolin-1, DLC-1, and NM23-H2 as putative antitumorigenic, progesterone-regulated genes for ovarian cancer cells by gene profiling. Oncogene 24: 1774-1787, 2005.

15. Chan LK, Ko FC, Sze KM, et al: Nuclear-targeted deleted in liver cancer 1 (DLC1) is less efficient in exerting its tumor suppressive activity both in vitro and in vivo. PLoS One 6: e25547, 2011.

16. Hers I, Wherlock M, Homma Y, et al: Identification of p122RhoGAP (deleted in liver cancer-1) Serine 322 as a substrate for protein kinase B and ribosomal S6 kinase in insulin-stimulated cells. J Biol Chem 281: 4762-4770, 2006.

17. Durkin ME, Yuan BZ, Zhou X, et al: DLC-1: a Rho GTPase-activating protein and tumour suppressor. J Cell Mol Med 11: 1185-1207, 2007.

18. Kim TY, Vigil D, Der CJ and Juliano RL: Role of DLC-1, a tumor suppressor protein with RhoGAP activity, in regulation of the cytoskeleton and cell motility. Cancer Metastasis Rev 28: 77-83, 2009.

19. Hall EH, Daugherty AE, Choi CK, et al: Tensin1 requires protein phosphatase-1alpha in addition to RhoGAP DLC-1 to control cell polarization, migration, and invasion. J Biol Chem 284: 34713-34722, 2009
20. Liu JB, Wu XM, Cai J, et al: CpG island methylator phenotype and Helicobacter pylori infection associated with gastric cancer. World J Gastroenterol 18: 5129-5134, 2012.

21. Wang MX, Wang HY, Zhao X, et al: Molecular detection of B-cell neoplasms by specific DNA methylation biomarkers. Int J Clin Exp Pathol 3: 265-279, 2010.

22. Liu JB, Zhang YX, Zhou SH, et al: $\mathrm{CpG}$ island methylator phenotype in plasma is associated with hepatocellular carcinoma prognosis. World J Gastroenterol 17: 4718-4724, 2011.

23. Ullmannova V and Popescu NC: Expression profile of the tumor suppressor genes DLC-1 and DLC-2 in solid tumors. Int J Oncol 29: 1127-1132, 2006.

24. Feng XL, Zhou W, Li H, et al: The DLC-1 -29A/T polymorphism is not associated with nasopharyngeal carcinoma risk in Chinese population. Genet Test 12: 345-349, 2008.

25. Calvisi DF, Pascale RM and Feo F: Dissection of signal transduction pathways as a tool for the development of targeted therapies of hepatocellular carcinoma. Rev Recent Clin Trials 2: 217-236, 2007.

26. Yuan BZ, Jefferson AM, Baldwin KT, et al: DLC-1 operates as a tumor suppressor gene in human non-small cell lung carcinomas. Oncogene 23: 1405-1411, 2004. 